\title{
GRAPHIC CORRELATION OF DEEP SEA AND SHALLOW MARINE DEPOSITS FROM THE CENTRAL AMERICAN ISTHMUS REGION: IMPLICATIONS FOR LATE NEOGENE PALEOCLIMATOLOGY
}

\author{
DOWSETT*, Harry J., U.S. Geological Survey, 970 National Center, Reston, VA \\ 22092, U.S.A.
}

The stratigraphic record in Panama and Costa Rica preserves the biologic and climatic changes associated with the formation of a major barrier to marine migration and ocean circulation. Creating a high resolution temporal framework within which stratigraphic sections found on the Isthmus can be interpreted is fundamental to our understanding the history and importance of these units.

The Isthmus contains rich marine macro- and microfaunas and floras on both the Pacific and Atlantic margins. Planktic foraminifers and calcareous nannofossils are common and often well preserved. Preliminary analysis of these fossils reveals a rich sedimentary record spanning the Late Miocene to Pleistocene. Multivariate statistical analyses of these assemblages provide environmental estimates. Unfortunately, traditional methods of biostratigraphy are limited in their ability to create a high resolution temporal framework for the region. For example, a majority of deposits analyzed can be placed in planktic foraminiferal zone N19 (early Pliocene). In order to answer paleobiologic and paleoclimatic questions one requires more precise correlations between sections and some indication of duration of sedimentation represented by various sections.

In an attempt to overcome the shortcomings of traditional biostratigraphic methods, the Graphic Correlation method has been applied to selected sequences on the Central American Isthmus. Graphic correlation (GC) is a procedure by which two sequences can be compared and correlated using a wide variety of stratigraphic information simultaneously. A GC model of late Neogene planktic foraminifer, calcareous nannofossil, and paleomagnetic reversal events has been produced through compositing of more than 26 deep sea cores and ocean margin sequences. Following routine GC procedures the positions of all fossil first and last occurrences from a number of sections on the Caribbean and Pacific sides of the Central American Isthmus (Panama and Costa Rica) have been recorded. These sections have been correlated to the GC model and hence, to each other, providing a temporal framework for the Isthmus units.

Selected sections were then correlated to other sequences such as near-by deep sea cores which have been analyzed for sea surface temperature and salinity to gain a better understanding of the overall paleoceanographic development of the region between 5 and $2 \mathrm{Ma}$. For example, correlation of units on the Caribbean side of the Isthmus with DSDP Site 502 indicates little to no change in sea surface temperatures during the entire time the Isthmus was reaching closure. Mid-to-high latitude sites exhibit amplification of warming with increasing latitude. The shoaling Isthmus, while having negligible effects on tropical marine temperatures, was responsible for increased meridional heat transport which resulted in a North Atlantic warming about $3 \mathrm{Ma}$. A general model for paleoceanographic changes during the time of closure will be discussed. 